\title{
Traditional Unani perspective of perceived insufficient milk (Qillatul Laban) and Galactogogues: A literary research with recent studies
}

\author{
Arshiya Sultana ${ }^{1, *}$, Khaleeq ur Rahman ${ }^{2}$ \\ ${ }^{1}$ Deptment of Amraze Niswan wa Ilmul Qabalat, National Institute of Unani Medicine, Bangalore - Karnataka, India; ${ }^{2}$ Deptment of \\ Ilmul Saidla, National Institute of Unani Medicine, Bangalore-Karnataka, India
}

\begin{abstract}
The most important reason mentioned for the early discontinuation of breast feeding and introduction of supplementary bottles is Perceived Insufficient Milk (PIM), which is relatively common in women. This is of public health concern because the use of breast milk substitutes increases the risk of morbidity and mortality among infants in developing countries and shortens birth intervals. Thus, a literary search in classical text for aetiopathogenesis, symptoms and treatment of PIM were appraised to implement in contemporary era. The classical Unani texts viz., Al Qanon fit Tib (Canon of Medicine), Al Hawi (Continens Liber), Zakheera Kharzam Shahi, Tarjuma Kamilus Sana, Tibbe Akbar, Akseer Azam, and Kitabul Kulliyat were reviewed. Further certain galactogogue herbs which are in use since antiquity such as fenugreek, cotton seeds, cumin, asparagus, black cumin etc were explored in different search engines on website for proven galactogogue activity. The causes of PIM are abnormal temperament of body or breast, anaemia, anxiety, depression, malnutrition etc. The principle treatment is treating the cause viz., the temperament is corrected by diet and drugs in abnormal temperament, elimination of humour is required in dominance of humour etc. The aforementioned drugs are proven scientifically for their galactogogue activity. The classical texts are having valuable information regarding PIM, which can be implemented in present era. Aforementioned Unani drugs are proven scientifically for with their galactogogue effect, however, clinical trials are scarce. Therefore, further randomized controlled clinical trials are recommended.
\end{abstract}

Keywords breast feeding, herbs, humour, Galactogogues, perceived milk insufficiency, Unani drugs

\section{INTRODUCTION}

Scientific evidence overpoweringly indicates that breast feeding confers significant health benefits to mother and child and is the ideal method for feeding and nurturing infants (Mennella and Pepino, 2010) but lactation insufficiency or failure is relatively common among women (Valdez et al., 2007). Oligogalactia or Perceived Insufficient Milk (PIM) is stated as one of the reasons mentioned most often by women throughout the world for the early discontinuation of breast feeding and/or for the introduction of supplementary bottles. They also stated that the incidence of oligogalactia has been estimated to range from 23 to $63 \%$ during the first four months after delivery (Segãoera-Millãn et al., 1994). This is of public health concern because the use of breast milk substitutes increases the risk of morbidity and mortality among infants in developing countries and shortens birth intervals. Furthermore, in populations with sufficient economic resources, inadequate lactation may have minor consequences on the growth and health of the infant, because adequate substitute nourishment is

*Correspondence: Arshiya Sultana

E-mail: drarshiya@yahoo.com,drasnium@gmail.com

Received Jenuary 10, 2014; Accepted August 22, 2014; Published

August 31, 2014

doi: http://dx.doi.org/10.5667/tang.2014.0003

(C)2014 by Association of Humanitas Medicine

This is an open access article under the CC BY-NC license.

(http://creativecommons.org/licenses/by-nc/3.0/) available. However, in populations of low socioeconomic status, inadequate lactation can lead to severe health problems in the newborn, whereas a full lactation can assure the normal growth and development of the newborn even in situations of deficient availability of nutrients for the general population (Valdez et al. 2007). Moreover, inadequate breast feeding contributes significantly to the high prevalence of malnutrition (Mathur and Dhingra, 2009). Malnutrition has been responsible, directly or indirectly for $60 \%$ of 109 million deaths among children, two-thirds being associated with inappropriate feeding practices (Desai et al., 2008). Though certain medicines like metoclopramide and domperidone are being used for augmenting lactation but are infrequently suggested in view of their limited efficacy prospects and major safety concern. Thus, there has been no effective western medical treatment for the illness so far (Zhoe et al., 2009).

However, from earliest times of mankind a multitude of plant galactagogues has been used in the folk medicine of all human cultures. In Unani system of medicine, details regarding PIM have been mentioned. Therefore, the aim of this literary search was to explore the classical text for aetiopathogenesis, symptoms and treatment of PIM were appraised to implement in contemporary era.

\section{MATERIALS AND METHODS}

The detail of lactation and PIM has been discussed in classical 
Unani text. The present article provides a literary search of aetiopathogenesis, symptoms and treatment of PIM from Unani classical treatises such as Avicenna's Canon of Medicine by Ibn Sina, Al Hawi fit Tib (Continen Libers) by Zakariya Razi, Zakeera Kharzam Shahi by Ismail Jurjani, Kamilus Sana by Al Majoosi, Haziq by Ajmal Khan etc. Furthermore, to update current approaches to treat, we conducted a search of the English-language literature on various websites such as pubmed, Medline google scholar for the terms, oligogalactia, perceived insufficient milk, mother's milk insufficiency, inadequate lactation, lactation failure and galactogogue herbs.

\section{RESULTS AND DISCUSSION}

It is well known fact that breastfeeding is recommend as human milk is species specific sustenance for the baby, produces optimal growth and development, and provides substantial protection from illness. Lactation is beneficial to mother's health and biologically supports a special mother/baby relationship. It is nature's gift to baby and meant for human infant (Dawn, 2004).

We are also well aware that babies who are not breastfed, or who are fed other foods too early may have an increased risk of bacterial meningitis, respiratory and ear infections, GI problems, necrotizing enterocolitis diarrhoea, botulism, obesity, urinary tract infection, and allergic skin disorders (Desai et al., 2008). Breastfeeding is inherent and most mothers adapt to it naturally. However, at the slightest problem encountered, mothers switch readily over to top/supplementary feeding. Mother often feels that they have insufficient milk, and faces numerous physical, emotional and logistical obstacles to breastfeeding and even small anxieties about milk supply can lead to lactation failure. Failing to receive the crucial breastfeeding support will also leads to lactation failure. PIM is one of the reasons mentioned most often by women throughout the world for the early discontinuation of breast feeding and/or for the introduction of supplementary bottles (Segãoera-Millãn et al., 1994).

\section{Results of aetiopathogenesis}

Unani scholars mentioned that maternal milk production is scanty in PIM. Ajmal Khan mentioned that PIM causes psychological and emotional trauma to the mother as the baby is not satisfied by the feeds, cries frequently, malnourished, and fall sick recurrently (Khan, 1983). Avicenna (Ibn Sina) in his treatise "Canon of Medicine" writes the causes of PIM should be evaluated as the milk production is scanty (Sina, 2010). He mentioned the causes of PIM are altered quality of blood where the blood element (madda khoon) is decreased, or distemperament (sue mizaj) or abnormal humours (ghair tabayi khilt). Ismail Jurjani was of opinion that simple or compound abnormal temperament of body or breast (sue mizaj saada or maddi of badan or pistani) are main causes of PIM (Jurjani, 2010). Razi (Zakariya Razi) describes the causes of PIM are alteration in quality of blood is because of anaemia (qillatut dam), dominance of bilious or phlegm humours (ghalbae safra or balgham) (Razi, 2001). Akbar Arzani describes the three causes for PIM are (1) anemia (qillatut dam) because of excessive heamorrhage caused by fasd or puerperal or menstrual blood loss or suffering from chronic disease, (2) excessive blood (kasrate dam); breasts are supplied by excessive blood and digestive faculty of breast is not able to digest the nutriment sufficiently, thereby leading to decrease in milk production and (3) simple or compound distemperament (sue mizaj saada or maddi) will lead to fasad dam. Abnormal temperament (sue mizaj) can be diagnosed by its sign and symptoms (Arzani, 2002). Azam Khan and Ajmal Khan describes PIM is also caused because of malnutrition, anxiety, depression, or excessive hemorrhage, which leads to weakness of attractive faculty (zoafe quwate jaziba) of breast, excessive intercourse, excessive heat, or less affection or mother and baby bonding for the child (Khan, 1983). In view of Kabiruddin and Azam Khan the milk production depends upon the quality of blood, correct mizaj of breast, hence, the cause might be fasad khoon, or kasrate khoon (Kabiruddin, 2003; Khan, 2011).

\section{Discussion of aetiopathogenesis}

The literary research showed that almost all Unani scholars in their respective treatises or compilations mentioned that the one of the causes of PIM is simple or compound distemperament of the whole body or breast or dominance of humours. In conventional medicine maternal factors mentioned for PIM is insufficient breast tissue, breast surgery (reduction), poor motivation, inappropriate management of local problems in the breast e.g. flat and sore nipples, engorgement (Narayanan 1985) retracted, short or too large nipples etc (Gupte,2004) .

It was also noted that Azam Khan (1983) said that anxiety, depression, excessive intercourse can also lead to PIM. Narayanan (1985) mentioned that sedation (also influences the baby), over anxiety, excessive fatigue, drugs e.g. oral contraceptives can lead to PIM. Previous or chronic psychiatric disorders including depression may recur in the postpartum period and interfere with maternal parenting abilities (Livingstone, 1997). Ajmal Khan (1983) also mentioned that PIM causes psychological and emotional trauma to the mother as the baby is not satisfied by the feeds, cries frequently, malnourished, and fall sick recurrently.

It has been proven in conventional medicine that primary inability to lactate by the mother is severe illnesses such as postpartum hemorrhage with Sheehan's syndrome, infection, or hypertension (Neifert, 2001). This opinion is in agreement with the causes mentioned by Zakariya Razi (2001), Ibn Sina (2010), and Akbar Arzani (2002) that anemia because of excessive hemorrhage, postpartum hemorrhage, etc, chronic illnesses and altered quality of blood can lead to PIM. Women suffering a PPH may experience a transient hypotensive insult and pituitary ischaemia and/or infarction resulting in inhibition of the hormonal triggering of lactogenesis Stage II by prolactin. In rare cases, women who bleed severely during childbirth may develop Sheehan's syndrome, or ischaemic necrosis of the pituitary gland, in particular of the anterior lobe, secondary to hypoperfusion. Failure to lactate or difficulties with lactation, due to absent or deficient prolactin secretion, are common initial symptoms of Sheehan's syndrome. In addition, elevated cortisol levels following such a stressful labour and delivery may also adversely affect lactogenesis Stage II. Delayed early contact between mother and baby following a complicated birth with PPH may also impact on a mother's ability to successfully establish and maintain breast feeding (Thompson et al., 2010)

Clinicians also need to consider the possibility of retained placental fragments that can be responsible for maintaining maternal progesterone levels sufficient to delay or inhibit secretory activation (lactogenesis II) (Kent et al., 2012). Moreover, it is an established fact that poor nutrition of the mother can lead to poor growth and development of the foetus, and to an insufficient quantity of milk (Parr, 1983).

\section{Results of symptoms}

Azam Khan mentioned that patients will have symptoms depending on the cause. The other symptoms of PIM are 
related to the baby for example baby is not satisfied by the feeds, cries frequently, and malnourished (Khan, 1983). Ibn Sina mentioned that if the cause is abnormally hot temperament, it would be identified from the signs and symptoms. When milk is scanty due to excessive heat in the breast, it would be recognized from their feel. In abnormal cold temperament, obstruction will be present or weakness in attractive faculty (zoafe quwate jaziba) of the body will be present (Sina, 2010). The colour of the milk is yellowish, the consistency decreases and burning is present when bilious humour is dominant. The milk is more white and sour in taste because of predominance of phlegm. The milk becomes scanty, more viscid and turbid in dominance of black bile humour (Arzani, 2002; Jurjani, 2010; Sina, 2010). Ismail Jurjani mentioned that sign and symptoms of dominance of phlegm, yellow and black bile in the blood are noticed (Jurjani, 2010).

\section{Discussion of symptoms}

The researchers mentioned that when milk is not sufficient, the infant does not feel satisfied after feedings, cries a lot, wants to nurse frequently, takes very long feedings and does not gain weight properly ( $<20 \mathrm{~g}$ a day) (Bernstein and Shelvo, 1996). The number of wet diapers a day (less than problems during lactation six to eight) and infrequent bowel movements, with a small amount of stools, which are dry and hard, indirectly indicate low intake of milk. The following signs indicate that an infant is not receiving enough milk in the first weeks of life: weight loss greater than $10 \%$ of the birth weight, not regaining birth weight up to two weeks of life, no urinary output for 24 hours, absence of yellow stools in the first week and clinical signs of dehydration are other symptoms of PIM (Bernstein and Shelvo, 1996).

\section{Results of diagnosis}

The dominance of humour (khilt) in PIM is diagnosed by examining the pulse and urine. If there is no dominance of humour, history of not taking the proper diet or taking cold or dry (barid or yabis) diet or excessive blood loss or psychological and emotional stress may be present (Kabiruddin, 2003; Khan, 2011).

\section{Discussion of diagnosis}

The diagnosis includes history taking, clinical examination and investigations. As mentioned by the Kabiruddin (2003) and Khan (2011) that malnutrition, anaemia, excessive blood loss because of postpartum hemorrhage, psychological and emotional stress affects the general health of mother that leads to PIM. In conventional medicine in interrogation of PIM number of questions are asked about mother's general health such as any medical conditions, complications during intra partum and postpartum period, any breast surgery, smoking, hypothyroidism, PCOS, breast changes in the pregnancy or after the birth. Anaemic women are less likely to continue breast feeding than other women (Amir, 2006).

\section{Results of management}

\section{Principle of treatment in Unani medicine}

Avicenna described that following is the mode in which feeding of infant is to be arranged. Whenever possible, the mother's milk should be given by suckling (Grunner, 1930). As the mother's milk is nearest to the blood from which the baby has grown up as the feotus. Such milk is better adapted for its further growth and development. The blood in mother's breast is converted into milk. This is beneficial for the infant and more attractive and acceptable to its constitution (Shah, 2007).
The treatment is advised according to the cause. In simple abnormal temperament (sue mizaj saada), the temperament (mizaj) is rectified by diet and drugs (Arzani, 2002; Jurjani, 2010; Sina, 2010). In distemperament (sue mizaj) of breast like in excessive heat (ghalbae hararat), cold pastes (mubarrid zamad) are applied locally, in excessive cold (ghalbae burdat), hot regimen (musakhkhin tadabir) is useful (Khan 2011). In dominance of khilt, elimination of humour (istrefagh khilt) is required (Jurjani, 2010). Majoosi said that in dominance of yellow bile (ghalbae safra), tanqiya of safra is advised (Majoosi, 2010). He also mentioned that to enhance the milk secretion, diet or drugs that increase the heat (hararat) of phlegm (khilte balgham) are useful. It increases the flow of milk toward the breast. In excessive hemorrhage, bleeding should be stopped. The production of milk is increased by using drugs which increases the production of semen (moallide mani) such as Lepidium iberis (tudri safaid), seeds of Papaver somniferum (tukhm kashkhash safaid), and the nutritious diet which is hot and moist (Arzani, 2002; Jurjani, 2010; Majoosi, 2010; Razi, 2001) states that all types of aphrodisiac (muqawwie bah advia) are useful.

\section{Diet}

Azam Khan mentioned that balance and nutritious diet is enough to treat PIM and drugs are not needed (Khan, 2011). The diet which is hot and moist such as milk, rice, chicken or honey with milk, faluda, halwa of egg yolk or carrot are useful. (Kabiruddin, 2003; Khan, 2011). If the milk production is less because of malnutrition and dryness, animal milk is useful (Jurjani 2010). Akbar Arzani advised diet such as milk, egg yolk, and chicken meat is used to increase blood production in anaemia (Arzani, 2002). In polycthemia (kasrate dam), venesection (fasd) and cupping (hijamah) are done and impurity of blood (fasad khoon) is to be rectified (blood purification). Ibn Sina diet such as barley soup, mixed with seeds of fennel (tukhme badiyan) root of fennel (bekh badiyan), seed of tukhme shibat, black cumin (kalonji) is useful in malnutrition (Sina, 2010).

\section{Advices}

Bed rest, avoid strenuous exercise and work. Avoid psychological stress (Jurjani, 2010).

\section{Discussion}

To increase milk production, Giugliani (2004) advice to improve latch on, if necessary, increase the frequency of feeding, eat a balanced diet, drink enough fluids and take a rest

\section{Treatment mentioned in Unani classical text}

If there are signs of cold temperament, obstruction or inadequate absorption, diet should be light (lateef) and slight hot things. Gentle cupping is also given under the breasts (Shah, 2007). In dominance of bile humour, seed kernel of bottle gourd grounded with water (sheera maghze tukhme kaddu), seeds of Portucala oleraceae grounded with water (sheera tukhme kurfa), pomegranate juice (abe anar), sikanjabeen sada and tursh drugs are useful or syrup of Nymphaea alba (sharbat niloufer) is administered orally. In dominance of phlegm humour, drugs with hot temperament such as fresh fennel (badiyan sabaz), shibat, and fresh Apium graveolens (karaf) is used. Soup of wheat flour (ard gandum) with fenugreek (hulba), fennel (badiyan) and honey is advised and then hab mushil is given (Kabiruddin, 2003; Khan, 2011). Ibn Sina mentioned that drug with first degree mizaj is useful in PIM (Sina, 2010). In dominance of black bile (ghalbae sauda),analgesic (musakhkhin) and moist (muratib) drugs such as soup (harira) 
of fig (anjeer), jowar (jaw), wheat (gandum) with almond oil (roghane badam) are useful (Kabiruddin, 2003; Khan, 2011). Milk production enhancing (mudir laban) drugs are useful such as Trigonella foenum-graecum (fenugreek), seeds of turnip (tukhme shalgam), ghee, green gram, etc (Razi, 2001).

\section{Galactagogues}

Galactagogues (or lactogogues) are medications or other substances believed to assist initiation, maintenance or augmentation of maternal milk production. Common indications for galactagogues are adoptive nursing (induction of lactation in a woman who was not pregnant with the current child), relactation (reestablishing milk supply after weaning), and increasing a faltering milk supply because of maternal or infant illness or separation (Montgomery and Wight, 2004).

The use of natural products believed to be able of increasing milk production has a long history. Galactagogues herbs mentioned in the Unani pharmacopeia are Withania somnnifera (Asgand), Lactus (Dooch) Madhuca indica (Gule Mahuwa), Nigella sativa (Kalonji), Vigna catiang (Lobia), Gossypium herbaceum (Pambadana), Asparagus racemosus (Satawar), Pastinaca secacu (Shaqaqul misri), Cheiranthus cheiri (Tudri) and Cuminum cyminum (Zeera safaid) (Said, 1997). The effect of certain galactagogues herbs are proven in pharmacological and clinical trials such as Nigella sativa Linn, Cuminum cyminum Linn, Asparagus racemosus Willd, Trigonella foenum-graecum Linn., etc (Huggin, 1998; Turkyılmaz et al., 2011).

\section{Discussion regarding Galactogogues used in Unani medicine and currently proven}

\section{Nigella sativa (Kalonji)}

The seeds of Nigella sativa showed marked galactagogue action in rats, as revealed by an increase in the weight of the litters of rats fed with the seeds. Histological examination showed more proliferation of acini and secretory activity in breast tissues of the mother rats fed with $N$. sativa seeds, the action being more potent than that of Jeera (Cuminum cyminum) which is also considered to be a galactagogue. In a study, the galactagogue principle was found to occur in the ether extract of the seed which, at a concentration of $1.8 \%$ showed a more powerful galactagogue effect than that induced by $0.5 \mathrm{mg}$ of estrogen injection given daily to lactating rats. Histology of the lactating breast tissues confirmed the enhanced secretory activity in rats on a diet of ether extract of Nigella sativa and estrogen as compared to controls. The rats fed with the ether extract showed more distension in the breast tissues (Khare, 2004).

\section{Asparagus racemosus Willd (Satawar)}

The milk yield in rats, cows, buffaloes (Kaikini et al., 1977; Kumar et al., 2008; Patel and Kanitkar, 1969; Sabnis et al., 1968) and goats (Vihan and Panwar, 1988) was increased by oral administration of roots of Asparagus racemosus Willd. The crude alcoholic extract of the roots increased the weight of mammary glands in post-partum and oestrogen-primed rats and the uterine weight in oestrogen-primed group (Sabnis et al., 1968).

The researchers in their double-blind randomized clinical trial evaluated Asparagus racemosus galactogogue effect in 60 lactating mothers by measurement of changes in their prolactin hormone level (Gupta and Shaw, 2011). They found that the oral administration of the research drug led to more than threefold increase in the prolactin hormone level of the subjects than the control group. The extract of Shatavari has been shown to increase both the weight of mammary lobulo-alveolar tissue and the milk yield in animal experiments. This effect was credited to the action of released corticosteroids or an increase in prolactin. Shatavarins I-V, the steroidal saponins, may be responsible for the hormonal like effect of Shatavari and explain its traditional use as a reproductive tonic (Gaitonde and Jetmalani, 1969; Pandey et al., 2005).

The presence of steroidal saponins and sapogenins constituents has been shown to directly contribute in the lactogenic effect of Asparagus racemosus (Goyal et al., 2003; Joshi, 1988).

\section{Gossypium herbaceum (Habbul Qutan)}

The studies conducted in buffaloes, showed that cotton seed feeding enhances the milk production significantly $(p<0.01)$ in comparison to concentrate mixture fed control group animals (Boodoo et al., 1990; Gaya et al., 1982; Sikka et al., 2001).

In single-blind, placebo-controlled, randomized clinical trial, kernel of Gossypium herbaceum, $10 \mathrm{~g}$ orally in three divided doses for 1 month showed 21(70\%), 7(23.33\%), and 2(6.67\%) mothers had complete relactation, partial relactation and no response correspondingly, whereas in the control group $4(26.67 \%)$ mothers had complete relactation, and $11(73.33 \%)$ mothers had no response. The volume of supplementary feeds to the infant in the test group was significantly reduced to $40 \pm 75.88 \mathrm{ml}$ after treatment from the baseline of the test group $(291.66 \pm 70.50 \mathrm{ml} ; p<0.001)$ and placebo (226.66 $\pm 149.84 \mathrm{ml} ; p<0.008$ ). Thus proving this herb is efficacious, safe and cost effective in augmenting lactation in PIM supply (Manjula et al., 2013).

\section{Trigonella foenum graecum (Hulba)}

Fenugreek is a natural product that is a member of the pea family. It has been used for a variety of indications, including treatment of cough, bronchitis, sore throats, and menstrual pain. Fenugreek is used in India and in some Middle Eastern countries as a spice and a medicine. It is believed to have a number of therapeutic uses, including anti-inflammatory, reconstituent and galactagogic effect (Zuppa et al., 2010). Anecdotal reports of the successful use of fenugreek as a galactagogue have been documented as far back as 1945 . However, formal published clinical data are lacking. A specific mechanism of action is unknown; however, it has been theorized that fenugreek may affect breast milk production by stimulating sweat production, and the breast is a modified sweat gland. In a clinical practice setting, Huggins describes the anecdotal use of the herb in at least 1200 women. Generally, all the women who consumed fenugreek reported an increase in milk production within 24 to 72 hours after initiation of therapy. Discontinuation of the herb can occur after milk production is stimulated to an appropriate level and maintained as long as breast stimulation and emptying continue. The recommended dose of fenugreek for use as a galactagogue is 2 to 3 capsules 3 times daily (Gabay, 2002).

In one of the study, the investigators asked 10 mothers to maintain a diary of the quantity of milk produced with a pump for a period of two weeks. In the first week, baseline milk production was evaluated; in the second week, mothers took fenugreek, 3 cups, three times daily. In the first week average quantities were $207 \mathrm{ml} /$ day, whereas, milk production in the second week averaged $464 \mathrm{ml} /$ day $(p=0.004)$. Unfortunately, the report excluded any information regarding the characteristics of the mothers enrolled in the study or the postpartum period during which the study was done. Nevertheless, the daily milk quantities reported during treatment do not seem to be particularly high (Zuppa et al., 
2010)

\section{CONCLUSION}

Human milk is species specific nourishment for the baby, produces optimum growth and development, and provides substantial protection from illness. Babies who are not breastfed, or who are fed other foods too early may have an increased risk of obesity, diarrhoea, GI problems, respiratory and ear infections, urinary tract infection, bacterial meningitis, botulism, necrotizing enterocolitis and allergic skin disorders. Hence, Mother's milk is very important for neonates. PIM is defined as the need to start top feeds for the baby within 3 months of delivery because of inadequate breast milk supply. PIM is also known as perceived insufficient milk. Unani classical texts are enormously enriched with the knowledge of lactation, lactation inadequacy and its treatment with galactagogue herbs such as fenugreek, cumin, cotton seed, Nigella sativa, etc. These herbs are recently proven pharmacologically and clinically for their galactagogue activity. Further randomized clinical trials in larger sample are recommended to prove their efficacy and safety.

\section{ACKNOWLEDGEMENTS}

We are thankful to the Director, National Institute of Unani Medicine and Dept of AYUSH for providing all facilities.

\section{CONFLICT OF INTEREST}

None.

\section{REFERENCES}

Amir LH. Breastfeeding-Managing 'supply' Difficulties. Australian Family Physician 2006;35:686-689.

Arzani MA. Mizane Tib. (New Delhi, India: Idarae Kitabus Shifa), 2002.

Bernstein D, Shelove SP. Pediatrics. (Pennsylvania, USA; Williams and Wilkins), 1996.

Boodoo AA, Ramjee R, Hulman B, Dolberg F, Rowe JB. Effect of supplements of balanced concentrates and cottonseed cake on milk production in mauritian villages. Livestock Research for Rural Development. 1990;2:7-14. Available at: http://www.lrrd.org/lrrd2/1/boodoo.htm (accessed on $02^{\text {th }}$ March 2014).

Dawn CS. Textbook of Obstetrics and Neonatology. $16^{\text {th }}$ ed. (Kolkata, India: Dawn Books) pp. 285-259, 2004.

Desai P, Malhotra N, Shah D. Principles and Practice of Obstetrics and Gynecology for Postgraduates. $3^{\text {rd }}$ ed. (New Delhi, India: Jaypee Brothers), 2008.

Desai P, Malhotra N, Shah D. Principles and Practice of Obstetrics and Gynecology for Postgraduates. (New Delhi, India: Jaypee Brothers), 2008.
Gabay MP. Galactagogues: Medications that Induce Lactation. J Hum Lact. 2002;18:274-279.

Gaitonde BB, Jetmalani MH. Antioxytocic action of saponin isolated from Asparagus racemosus Willd. (Shatavari) on uterine muscle. Arch Int Pharmacodyn Ther. 1969;179:121-129.

Gaya H, Hulman B, Preston TR. The Value for milk production of different feed supplements: Effect of cereal protein concentrate, poultry litter and oil seed meal. Tropical Animal Production. 1982;7:134-137. Available at: http://www.utafoundation.org/UTAINFO1/TAP/TAP72/72-

134.pdf (accessed on $07^{\text {th }}$ October 2014)

Giugliani ERJ. Common Problems during Lactation and Their management. Journal de Pediatria. 2004;80:147-154.

Goyal RK, Singh J, Harbans L. Asparagus racemosus an update, Review. Indian J Med Sci. 2003;57:408-414.

Grunner O C. A Treatise of the Canon of Medicine of Avicenna. (London, England: Luzac \& Co), 1930.

Gupta M, Shaw B. A Double-Blind Randomized Clinical Trial for Evaluation of Galactagogue Activity of Asparagus racemosus Willd. Iran J Pharm Res. 2011;10:167-172.

Gupte S. The Short Textbook of Pediatrics. (New Delhi, India: Jaypee Brothers), 2004.

Huggins K. Fenugreek: One Remedy for Low Milk Production. Rental Roundup. 1998;15:16-17.

Joshi JDS. Chemistry of ayurvedic crude drugs: Part VIII: Shatavari: 2. Structure elucidation of bioactive shatavarin I and other glycosides. Indian J Chem. 1998;27:12-16.

Jurjani AH Tarjumae Zakheera Khawarzam Shahi (Urdu Trans: Khan HH). (New Delhi, India: Idarae Kitabus Shifa), 2010.

Kabiruddin M. Al Akseer. Vol. 2. (New Delhi, India: Aijaz Publication), 2003.

Kaikini AS, Pargaonkar DR, Dindorkar CV. Studies on oestrus and oestrous cycle in nondescript (Native) Cows Proc. $1^{\text {st }}$ Asian Congress on Fertility, and Sterility, Bombay. pp. 19-24, 1977.

Kent JC, Prime D K, Garbin CP. Principles for Maintaining or Increasing Breast Milk Production JOGNN 2012;41:114-121. Available at: http://jognn.awhonn.org (accessed on $23^{\text {th }}$ December 2013).

Khan A. Akseere Azam. (New Delhi, India: Idarae Kitabus Shifa), 2011.

Khan A. Haziq. (Karachi, Pakistan: Madina Publishing Company), 1983.

Khare CP. Indian Herbal Remedies: Rational Western Therapy, Ayurvedic, and Other Traditional Usage, Botany. (New York, USA: Springer), 2004.

Kumar S, Mehla RK, Dang AK. Use of Shatavari (Asparagus racemosus) as a galactopoietic and therapeutic herb - A review Agric Rev. 2008;29:132-138. 
Livingstone V. Neonatal insufficient breast milk syndrome. Obstetrics and Gynecology. Medicine North America March 1997. Available at: http://breastfeedingclinic.com/pdf/Neonatal\%20insufficient\%2 0breast\%20milk\%20syndrome.pdf (accessed on $13^{\text {th }}$ December 2011).

Majoosi AA. Kamilus Sana. (Urdu Trans: Kantoori GH.) (New Delhi, India: Central Council of Research in Unani Medicine), 2010.

Manjula S, Sultana A, Rahman K. Clinical efficacy of Gossypium herbaceum L. seeds in perceived insufficient milk (PIM) supply: A randomized single-blind placebo-controlled study. Orient Pharm Exp Med. 2014;14:77-85.

Mathur NB, Dhingra D. Perceived Breast Milk Insufficiency in Mothers of Neonates Hospitalized in Neonatal Intensive Care Unit. Indian J Pediatr. 2009;76:1003-1006.

Mennella JA, Pepino MY. Breastfeeding and Prolactin Levels in Lactating Women with a Family History of Alcoholism. Pediatrics. 2010;125;e1162.

Montgomery A, Wight N. Use of Galactagogues in Initiating or Augmenting Maternal Milk Supply. The Academy of Breastfeeding Medicine Protocol Committee. 2004. Available at: http://jgh.ca/uploads/breastfeeding/abmgalactogogues.pdf (accessed on $3^{\text {th }}$ December 2011).

Narayanan I. Rational approach to lactational failure. Indian J Pediatr. 1985;52:167-170.

Neifert M R. Prevention of breast feeding tragedies. Pediatr Clin North Am. 2001;48:273-297.

Pandey SK, Sahay A, Pandey RS, Tripathi YB. Effect of Asparagus racemosus rhizome (Shatavari) on mammary gland and genital organs of pregnant rat. Phytother Res. 2005;19: 721-724.

Parr RM. Trace Elements in Human Milk. IAEA BULLETIN 1983;25:7-15. Available at: http://www.iaea.org /Publications/Magazines/Bulletin/Bull252/25205880715.pdf (accessed on $3^{\text {rd }}$ December 2011).

Patel AB, Kanitkar UK. Asparagus racemosus Willd. from Bordi as a galactogogue in buffaloes. Indian Vet J. 1969;46: 718-721.

Razi ABZ Kitab al Hawi fi al-tibb. Vol. 7. (New Delhi, India: Central Council of Research in Unani Medicine), 2001.
Sabnis PS, Gaitondi BB, Jetmalani M. Effect of alcoholic extract of Asparagus racemosus on mammary glands of rats. Indian J Exptl Biol. 1968;6:55-57.

Said M. Hamdard Pharmacopoeia of Eastern Medicine. (Delhi, India: Sri Satguru Publications), 1997.

Segãoera-Millãn S, Dewey KG, Perez-Escamilla RJ. Factors Associated with Perceived Insufficient Milk in a Low-Income urban Population in Mexico. Nutrition. 1994;124:202-212.

Shah M. The General Principles of Avicenna's Canon of Medicine. (New Delhi, India: Idarae Kitabus Shifa), 2007.

Sikka P, Saxena NK, Gupta R, Sethi RK, Lall D. Studied on Milk Allantoin and Uric Acid in Relation to Feeding Regimens and Production Performance in Buffaloes. Asian-Aust J Anim Sci. 2001;14:1634-1637. Available at: http://www. ajas.info/upload/pdf/14-245.pdf (accessed on $2^{\text {th }}$ March 2012).

Sina I. Al Qanoon fit Tib. (Trans: Kantoori GH.) Vol.1 (New Delhi, India: Idarae Kitabus Shifa), 2010.

Thompson JF, Heal LJ, Robert CL, Ellwood DA. Women's breastfeeding experiences following a significant primary postpartum haemorrhage: A multicentre cohort study. Int Breastfeed J. 2010;5:5.

Turkyılmaz C, Onal E, Hirfanoglu IM, Turan O, Koç E, Ergenekon E, Atalay Y. The effect of galactagogue herbal tea on breast milk production and short-term catch-up of birth weight in the first week of life. J Altern Complement Med. 2011;17:139-142.

Valdez SR, Penissi A B, Deis RP, Jahn GA. Hormonal Profile and Reproductive Performance in Lactation Deficient (OFA $\mathrm{hr} / \mathrm{hr}$ ) and Normal (Sprague-Dawley) Female Rats. Reproduction. 2007;133:827-840.

Vihan VS, Panwar HS. A note on galactogogue activity of Asparagus racemosus in lactating goats. Indian J Animal Health. 1988;27:177-178.

Zhou HY, Li L, Li D, Li X, Meng HJ, Gao XM, Jiang HJ, Cao LR, Zhu YL. Clincial observation on the treatment of postcesarean hypogalactia by Auricular points sticking pressing. Clin J Integr Med. 2009;15:117-120.

Zuppa AA, Sindico P, Orchi C, Carducci C, Cardiello V, Romagnoli C. Safety and Efficacy of Galactagogues: Substances that Induce, Maintain and Increase Breast Milk Production. J Pharm Pharmaceut Sci. 2010;13:162-174. 